Research Article

\title{
Social and Demographic Associates of School Bully Behavior in Indian Pupils
}

\author{
Bidushi Mishra', Nidhi Dinesh Sinha' ${ }^{2}$ Gitisha Mishra ${ }^{3}$, Badrinarayan Mishra ${ }^{4}$ \\ ${ }^{1}$ 2nd year BDS, Peoples College of Dental Sciences, Peoples University, Bhopal, Madhya Pradesh, India. \\ ${ }^{2}$ Associate Professor, Department of Dentistry, Ruxmaniben Deepchand Gardi Medical College, Ujjain, Madhya Pradesh, India. \\ ${ }^{3} 12^{\text {th }}$ Science, Carmel Convent, Ujjain, Madhya Pradesh, India. \\ ${ }^{4}$ Professor Community Medicine, Department of Community Medicine, Ruxmaniben Deepchand Gardi Medical College, Ujjain, \\ Madhya Pradesh, India.
}

DOI: https://doi.org/10.24321/2455.9199.202101

\section{I $\quad \mathbf{N} \quad \mathbf{F} \quad \mathbf{O}$}

\section{Corresponding Author:}

Badrinarayan Mishra, Community Medicine, Department of Community Medicine, Ruxmaniben Deepchand Gardi Medical College, Ujjain, Madhya Pradesh, India.

E-mail Id:

badrinmishra@gmail.com

Orcid Id:

https://orcid.org/0000-0001-6956-0469

How to cite this article:

Mishra B, Sinha DN, Mishra G, Mishra B. Social and Demographic Associates of School Bully Behavior in Indian Pupils. Int J HealthCare Edu \& Med Inform. 2021;8(1):1-7.

Date of Submission: 2020-12-25

Date of Acceptance: 2021-03-20

\section{$\begin{array}{llllllllllll}\mathbf{A} & \mathbf{B} & \mathbf{S} & \mathbf{T} & \mathbf{R} & \mathbf{A} & \mathbf{C} & \mathbf{T}\end{array}$}

Bully activities at school have a long-term detrimental effect. Though the types and manifests of this damaging behavior are studied, there is a paucity of evidence on its social determinants.

Aim and Objective: This study explored the socio-demographic determinants of school-bullying in a central India district.

Methods: Cross-sectional data were compiled over one year from 480 participants by simple random method from urban and rural schools. The bully Prevalence Questionnaire (BPQ) and socio-demographic information questionnaire were used. Questionnaires in English and Hindi language were commissioned to cater to the participants' need. SPSS Vs. 21 was used for data analysis at $\mathrm{P} \leq 0.05$.

Results: The urban vs. rural divide was noticable ( $\chi 2 ; p-0.033)$. Boys involvement was dominant ( $66.2 \% \mathrm{vs}, 30.4 \%$ and $\chi 2 ; p-0.00)$. Father's occupation and family income were the important social determinants $(\chi 2$ value $p-0.00$, ANOVA $p-0.02$, and 0.05$)$. Victimization per se was noticed more among girls as compared to boy's ( $r$.310** vs. $\left..144^{*}\right)$. Children of unskilled workers were more often a party to school bullying $\left(r .317^{* *}\right)$. Father and mother's educational levels were strong players in deciding students' prosocial skills (ANOVA p -0.014 and 0.00). Participants' self-esteem score was influenced by family income (ANOVA p -0.00).

Conclusion: Involvement of boys at high number was a matter of concern. The skewed number in favour of children from unskilled working families necessitates the attention of social reformists and policymakers. Improved education of parents is also vital in curbing this social evil.

Keywords: School Bully Behaviors, Demographic Factors, Social Determinants 


\section{Introduction}

Most health-related events (50\% to $90 \%$ ) are determined by social and demographic factors. ${ }^{1-4}$ In the last two decades, these are emphasized under the term 'Social Determinants of Health (SDH)' that is broadly defined as conditions or circumstances in which people are born, grow, live, work, and age. ${ }^{5,6}$ Socio-political and economic factors are its proponents and medical sociology, social demography, and social epidemiology are its interpreters. ${ }^{5,7}$

Bullying, a psychosocial condition, is also influenced by $\mathrm{SDH}$. Though the role of SDH in this regard is explored to some extent in developed nations there is a serious dearth of evidence in developing nations including India. Evidence generated so far indicates that the individual character of students engaged in this psychosocial aberration has a strong connection to the ecosystem with which they interact. The two parts of the ecosystem which has a detrimental effect on behavior development in children are the 'exosystem' made up of neighbourhood and community environment, and the 'macrosystem' made up of the social and cultural backgrounds. ${ }^{8-10}$ As the ecosystem is diverse the need to explore them from different social, cultural and demographic contexts is important.

India has a vast population of adolescents of 243 million ( $21 \%$ of the Indian population). ${ }^{9}$ The educational policy is constantly encouraging them to get enrolled for formal education through school enrolment. ${ }^{10-12}$ The recently passed National Educational Policy 2020, aims at achieving $100 \%$ Gross Enrolment Ratio for all school education by 2030 from the present level of $53 \% .{ }^{12}$ This proactive educational approach is and will not be free from some of its backlash like the increasing prevalence of bullying at the school level. Though the manifests of bullying are being studied in reasonable depth there exists a gap in knowledge relating to the diverse social, economic and cultural backdrops of the students and their association with school bullying.

\section{Methods}

Six schools 3 from urban and 3 from rural areas of Ujjain districts of the state of Madhya Pradesh, India were randomly picked by a computer-generated number from the list of schools made available by the district educational officer. Parental and school consents were obtained in writing before the initiation of the participant enrolment. Participants in equal numbers across geography, gender, class/ standard in school were ensured by stratified random selection. Prevalence based formulae( $\mathrm{P}=31.4 \%)$ for sample size calculation $\left(\mathrm{N}=4 \mathrm{pq} / \mathrm{I}^{2}\right)$ was used to which $10 \%$ extra population was added to address the issue of dropouts. ${ }^{13}$ The final number was reached by rounding up to the nearest upper digit which came out to be 480 .

Inclusion and Exclusion Criteria: Participants from $6^{\text {th }}$ to $10^{\text {th }}$ standard with written parental consent and free from major morbid conditions were enrolled.

Blinded data coding and analysis were done to minimize bias. The level of statistical significance was determined at $p \leq 0.05$ and data was analyzed by SPSS version 25 Chicago Inc USA. Results are expressed in frequency, percentage, $\chi 2$ value, Pearson $r$ and ANOVA F and level of significance.

\section{Results}

$66.2 \%$ of boys were involved in one or the other form of bullying. When compared with girls this figure was statistically significant ( $\chi 2 \mathrm{p}$ 0.000). A comparison of urban vs, rural demography showed prominence of all bully activities in urban schools and the most prominent among them was Victimization ( $\chi 2 \mathrm{p}-0.03)$. From a social and economic angle, children illiterate (52.9\% to $57.1 \%)$, unemployed parents (61\%) and low-income groups (61,7\%) represented a higher percentage in school bullysim. On chisquare analysis, it was affirmed that the father's occupation and family income were significant associates of school bullying ( $\chi 2 \mathrm{p}-0.00)$. The details of socio-demographic associates of school bully activities in study participants are presented in Table 1.

A strong to a very strong positive relationship was noted between bully and victim activities in students from all localities, both genders, in children of unskilled workers, and across all income groups except the upper-middle class. Participants' prosocial scores showed a strong negative relationship with both bully and victim scores in urban students, boys, and students from the middle socioeconomic class. While girl students' self-esteem was a negating factor for school bullying $(r,-0.144)$, their poor general health was positively related to it $(r, 0.162)$. The details are presented in Table 2.

Table I.Chi-square Test (X2) Association of Socio-demographic Profile of Pupils (participants) with Different Types of Bully Behaviours

\begin{tabular}{|c|c|c|c|c|c|}
\hline Variable & Bully & Victim & Bully Victim & Bystander/ Not involved & p-value $\left(\chi^{2}\right)$ Total (\%) \\
\hline \multicolumn{7}{|c|}{ Residence/ Location } & $(\mathbf{p}-\mathbf{0 . 0 3 3 )}$ \\
\hline Urban & $25(10.4)$ & $60(25)$ & $32(13.3)$ & $123(51.3)$ & $240(100)$ \\
\hline Rural & $35(14.6)$ & $37(15.4)$ & $43(17.9)$ & $125(52.1)$ & $240(100)$ \\
\hline \multicolumn{7}{|c|}{ Gender } & $(p-0.000)$ \\
\hline Boys & $31(12.9)$ & $72(30)$ & $56(23.3)$ & $81(33.8)$ & $240(100)$ \\
\hline
\end{tabular}




\begin{tabular}{|c|c|c|c|c|c|}
\hline Girls & $29(12.1)$ & $25(10.4)$ & $19(7.9)$ & $167(69.6)$ & $240(100)$ \\
\hline \multicolumn{5}{|c|}{ Father's Education } & $(p-0.396)$ \\
\hline Illiterate & $8(14.3)$ & $12(21.4)$ & $12(21.4)$ & $24(42.9)$ & $56(100)$ \\
\hline middle school & $28(11.2)$ & $57(22.8)$ & $40(16.0)$ & $125(50)$ & $250(100)$ \\
\hline H.S. and H.S.S. & $15(11.5)$ & $21(16.2)$ & $17(13.1)$ & $77(59.2)$ & $130(100)$ \\
\hline$\geq$ Graduate & $9(20.5)$ & $7(15.9)$ & $6(13.6)$ & $22(50)$ & $44(100)$ \\
\hline \multicolumn{5}{|c|}{ Mother's Education } & $(p-0.47) *$ \\
\hline Illiterate & $19(13.8)$ & $27(19.6)$ & $27(19.6)$ & $65(47.1)$ & $138(100)$ \\
\hline middle school & $24(10.1)$ & $49(20.7)$ & $35(14.8)$ & $129(54.4)$ & $237(100)$ \\
\hline H.S. and H.S.S. & $12(16.4)$ & $14(19.2)$ & $8(11)$ & $39(53.4)$ & $73(100)$ \\
\hline$\geq$ Graduate & $5(15.6)$ & 7 (21.9) & $5(15.6)$ & $15(46.9)$ & $32(100)$ \\
\hline \multicolumn{5}{|c|}{ Father Occupation } & $(p-0.004)$ \\
\hline Unemployed & $8(19.5)$ & $9(22)$ & $8(19.5)$ & $16(39)$ & $41(100)$ \\
\hline Unskilled & $28(9.1)$ & $56(18.1)$ & $41(13.3)$ & $184(59.5)$ & 309 (100) \\
\hline Skilled worker & $15(19)$ & $18(22.8)$ & $17(21.5)$ & $29(36.7)$ & $79(100)$ \\
\hline Other & $9(17.6)$ & $14(27.5)$ & $9(17.6)$ & $19(37.3)$ & $51(100)$ \\
\hline \multicolumn{5}{|c|}{ Mother's Occupation } & $(p-0.801)$ \\
\hline Unemployed & $26(12.5)$ & $47(22.6)$ & $32(15.4)$ & $103(49.5)$ & $208(100)$ \\
\hline Unskilled & $17(10)$ & $35(20.6)$ & $28(16.5)$ & $90(52.9)$ & $170(100)$ \\
\hline Skilled worker & $10(16.1)$ & $8(12.9)$ & $9(14.5)$ & $35(56.5)$ & $62(100)$ \\
\hline Other & $7(17.5)$ & $7(17.5)$ & $6(15)$ & $20(50)$ & $40(100)$ \\
\hline \multicolumn{5}{|c|}{ Family Income } & $(p-.000)^{*}$ \\
\hline Low & $11(10.3)$ & $29(27.1)$ & $26(24.3)$ & $41(38.3)$ & $107(100)$ \\
\hline Middle & 39 (14.9) & $40(15.3)$ & $28(10.7)$ & $155(59.2)$ & $262(100)$ \\
\hline Average & $4(5.1)$ & $22(28.2)$ & $16(20.5)$ & $36(46.2)$ & $78(100)$ \\
\hline High & $6(18.2)$ & $6(18.2)$ & $5(15.2)$ & $16(48.5)$ & $33(100)$ \\
\hline
\end{tabular}

${ }^{*}$ Chi-square test was applied after merging the rows. Figures in parentheses indicate \%

Table 2.Pearson's Correlation between the Bully and Other Scores with Sociodemographic Variables

\begin{tabular}{|c|c|c|c|c|c|c|c|c|c|}
\hline \multirow{3}{*}{ Variable } & \multirow{3}{*}{ Number } & \multicolumn{8}{|c|}{ Scores } \\
\hline & & \multicolumn{2}{|c|}{ Victim score } & \multicolumn{2}{|c|}{ Pro-social score } & \multicolumn{2}{|c|}{ Self-esteem score } & \multicolumn{2}{|c|}{ GHQ-12 score } \\
\hline & & $\mathbf{r}$ & $\mathbf{p}$ & $r$ & p & $r$ & p & $\mathbf{r}$ & $\mathbf{p}$ \\
\hline \multicolumn{10}{|c|}{ Area/ Location } \\
\hline Urban & 240 & $.216^{* *}$ & .001 & $-.200^{* *}$ & .002 & -.013 & .840 & .075 & .248 \\
\hline Rural & 240 & $.319^{* *}$ & .000 & -.094 & .146 & -.071 & .275 & .085 & .190 \\
\hline \multicolumn{10}{|c|}{ Gender } \\
\hline Boys & 240 & $.144^{*}$ & .026 & $-.165^{*}$ & .010 & .057 & .376 & -.017 & .791 \\
\hline Girls & 240 & $.310^{* *}$ & .000 & -.092 & .153 & $-.144^{*}$ & .026 & $.162^{*}$ & .012 \\
\hline \multicolumn{10}{|c|}{ Father's Occupation } \\
\hline Unemployed & 41 & .096 & .552 & .074 & .646 & .037 & .820 & -.085 & .598 \\
\hline $\begin{array}{l}\text { Unskilled } \\
\text { workers }\end{array}$ & 309 & $.31^{7^{* *}}$ & .000 & $-.142^{*}$ & .012 & -.094 & .100 & .036 & .533 \\
\hline Skilled worker & 79 & .152 & .182 & $-.278^{*}$ & .013 & .118 & .302 & $.366^{* *}$ & .001 \\
\hline
\end{tabular}




\begin{tabular}{|c|c|c|c|c|c|c|c|c|c|c|c|}
\hline Others & 51 & .217 & .125 & -.252 & .075 & -.077 & .592 & -.017 & .908 \\
\hline \multicolumn{8}{|c|}{ Family Income } \\
\hline Low & 107 & $0.233^{*}$ & .016 & -.109 & .264 & .078 & .425 & .094 & .337 \\
\hline Middle & 262 & $.249^{* *}$ & .000 & $-.166^{* *}$ & .007 & -.039 & .532 & .103 & .097 \\
\hline Average/upper & 78 & .210 & .065 & -.184 & .106 & -.143 & .211 & .099 & .391 \\
\hline middle High & 33 & $0.476^{* *}$ & .005 & -.136 & .451 & .122 & .499 & -.165 & .358 \\
\hline
\end{tabular}

$r=$ correlation coefficient; ${ }^{*}$ significant at $p-0.05 ;^{* *}$ significant at $p-0.000$ level

Table 3.One Way “ANOVA Test” Demonstrating the Existence of Relationship between

Outcome Variables and Social Determinants

\begin{tabular}{|c|c|c|c|c|c|c|}
\hline \multicolumn{7}{|c|}{ Bully score } \\
\hline Study Variables & & Sum of Squares & Df & Mean Square & F & Sig. \\
\hline Father's Occupation & Between Groups & 37.508 & 3 & 12.503 & 3.218 & 0.02 \\
\hline Family Income & Between Groups & 30.574 & 3 & 10.191 & 2.613 & 0.05 \\
\hline \multicolumn{7}{|c|}{ Victimization } \\
\hline Study Variables & & Sum of Squares & Df & Mean Square & F & Sig. \\
\hline Father's Occupation & Between Groups & 40.951 & 3 & 13.650 & 1.797 & 0.14 \\
\hline Family Income & Between Groups & 225.482 & 3 & 75.161 & 10.426 & 0.00 \\
\hline \multicolumn{7}{|c|}{ Prosocial } \\
\hline Study Variables & \multicolumn{7}{|c|}{ Sum of Squares } & Df & Mean Square & F & Sig. \\
\hline Father's Education & Between Groups & 65.057 & 3 & 21.686 & 3.597 & 0.01 \\
\hline Mother's Education & Between Groups & 88.772 & 3 & 29.591 & 4.948 & 0.00 \\
\hline \multicolumn{7}{|c|}{ Self-esteem score } \\
\hline Variable & Category & Sum of Squares & Df & Mean Square & F & Sig. \\
\hline Family Income & Between Groups & 331.011 & 3 & 110.337 & 6.562 & 0.00 \\
\hline
\end{tabular}

The outcome variables like bully scores, victim scores, prosocial and self-esteem scores and their estimated (oneway ANOVA) relationship with pertinent sociodemographic factors (social determinants) are presented in Table 3. It was noted that the father's education and family income were leading propagators to bully scores(activity), victimization was related only to family income ( $p-0.00)$. Parental education (both father and mother) were a strong prognosticator to prosocial behavior in the child. Family income was a strong predictor for the self-esteem of the child too.

\section{Discussion}

Safe school environment is the need of the day. It provides the best environment for learning and self-growth. Ensuring such an ambience is a win-win position for the all-stake holders. The end product is a boon to the immediate and far-reaching society.

But there are many a slip between the cup and the lip. The preponderance of school bullying is a situation that is criminal to be ignored. Just exploring its types, their prevalence, demonstrates are of little use unless the root cause is investigated. Here a valiant effort is made to find the social determinants of this demonic misconduct which will strengthen the hand of different stakeholders in permanently solving the jigsaw.

The role of SDH in health and disease has drawn global attention in the last 2 decades. This major player was and is a constant and dominant contributor to most healthrelated events, be it infectious, non-communicable or behavioral. Sociology, demography and their epidemiology are the focal points in the identification of this under current. ${ }^{5,6}$ WHO (World Health Organization's) Commission on Social Determinants of Health also endorses the abovementioned mutually non-exclusive explanations for SDH by their theoretical explanations of psychosocial approaches; social production of disease/political economy of health; and eco-social frameworks. ${ }^{14}$ Braveman P and Gottlieb L. called this (SDH) as 'the causes of the causes' or 'mother of all causes' for disease causation. ${ }^{15}$

The role of SDH in shaping the present and future health of school children including psychosocial health is substantiated by the WHO's (World Health Organizations) $6^{\text {th }}$ report on Health Behavior in School-Aged Children 
(HBSC) study. ${ }^{16}$ Social determinants which include "any nonmedical factors influencing health," like individual characteristics such as gender, race/ethnicity, parental educational attainment and occupational status exhibit a two-way relationship with the psychological(mental) health of school children. ${ }^{17-20}$ Despite visible gains in some sects, the $6^{\text {th }} \mathrm{HBSC}$ reports point to the continuing influence of SDH on issues of overweight-obesity, self-esteem, life satisfaction, substance misuse and bullying. ${ }^{16}$

Bulling in the present study was significantly prevalent in urban areas $(p-0,03)$. Literature provides ample support to this claim. Bradshaw in 2009 reported that safety indicators decline in bigger schools commonly located in urban settings, which have an unfavourable proportion of students to teachers. ${ }^{21}$ Mazur and Tabak (2017) too observed a higher prevalence of school bullying in urban settings. $^{22}$

It is commonly reported that boys are more likely to be involved in bullying others than are girls. ${ }^{18,25}$ In our study, we observed $66.2 \%$ of boys' vs $30.4 \%$ of girls (p-0.00) were party to bully activities. Victimization and bully-victim category were at a staggeringly high level of $30 \%$ and $23.3 \%$ respectively in boys as compared to girls $(p-0.00)$. Cook et al. (2010) found a correlation of gender (boys) with the bully role of 0.18 , with the bully/victim role of 0.10 , and with the victim role of 0.06 , indicating a higher prevalence of boys for all three roles. ${ }^{24}$

The concluding study demonstrates that children of the unemployed father (61\%, ANOVA p- 0.02) and from lowincome families (61.7\%, ANOVA p - 0.05) showed a higher association with the bully score (Table 3). Tippett and Wolke in their meta-analysis observed that odds for children from low socioeconomic households were high for victimization and bully-victim activities (victims odds ratio [OR] = 1.40; $95 \%$ confidence interval $[\mathrm{Cl}]=1.24,1.58$ and bully-victims $\mathrm{OR}=1.54 ; 95 \% \mathrm{Cl}=1.36,1.74) .{ }^{25}$ The present study also highlighted the role of low-income families in pupils' victimization (ANOVA $p-0.00$ ). The meta-analysis results by Tippett and Wolke (2015) indicated that victimization was positively associated with low SES (OR $=1.52 ; 95 \% \mathrm{Cl}$ $=1.36,1.71) \cdot{ }^{25}$

Unemployment and low income are directly related to parental education. This study observed a lack of parental education (illiteracy) recording a high point prevalence with school bullying behavior in their children $152.9 \%$ for illiterate mothers and $57.1 \%$ for illiterate fathers). According to Chaux, et al (2009), a high level of income imbalance in the population lead to power imbalances which was a major factor to instigate violence in urban dwellings. School children overly observe and replicate this disrupted behavior that has stemmed from social inequality at their level. ${ }^{26}$
The prosocial score is of protective significance for behavioral disorders including school bullying. The concluded study affirmed this observation by demonstrating a negative relationship of prosocial scores with both bully and victim scores which were further validated by one-way ANOVA findings (Tables 2 and 3). Card, 2003 in his meta-analysis found that children with low levels of prosocial behavior are more likely to be victimized. ${ }^{27}$

Income generation is usually directly proportional to education and types of occupation. Here it was observed that students from sound income families demonstrated high self-esteem and this like prosocial score acted as a protective factor against school bullying (Table 3). Cook et al., 2010 in their meta-analysis pointed out that low self-esteem leads to aggression, including bullying. ${ }^{24,28-31}$

Strengths and Limitations: Pretested pilot studied questionnaire, trained and single observer (data collector), robust sampling techniques, blinded coding and data analysis were the strength of the study. Bias due to cross-sectional design is an important limitation worth mentioning.

\section{Conclusion}

Bullying at school is as old as the institution itself. But the empirical study of bullying behavior is a relatively recent field and is still in transition. Over the past few decades, research has significantly improved understanding of what bullying behavior is, how it can be measured, and the critical contextual factors that are involved in it. While there is no quick fix and one-size-fits-all solution to this complex problem, the evidence supports preventive and interventional policy and practice based on scientific inputs should curb this nuisance to a great extent. From the SDH point of view, multiprong interventions aimed at addressing social inequalities of the nature of access to education, employment opportunities, health services, safe and secure housing and neighbourhoods will go a long way in finding a lasting solution. In this regard, the WHO initiative of 'Health 2020' has taken a leaf out of the sixth international HBSC report which advocates acting in increasing understanding of inequalities due to age, gender and SES to give a befitting reply to this social demon. In future we expect this to be a universal move for all WHO regions.

\section{Highlights}

- Social determinants like parental education, occupation, and incomes are strong players in determining bully behavior in school children

- Students from urban schools and boys demonstrated a strong association with school bullying

\section{Acknowledgement}

We are grateful to the inspector of the school, all principals 
of participating schools and the participants and their parents for their cooperation and consent.

\section{Ethical Permission}

The IEC (institutional ethical committee of R D Gardi Medical College) permitted the conduction of this study vid version number 225.

\section{Source of Funding: None \\ Conflict of Interest: None \\ References}

1. CSDH [Internet]. Closing the Gap in a Generation: Health Equity Through Action on the Social Determinants of Health. Final Report of the Commission on Social Determinants of Health. Geneva: World Health Organization; 2008.

2. Lucyk K, McLaren L. Taking stock of the social determinants of health: A scoping review. PLoS One. 2017;12(5):e0177306. [Pubmed] [Google Scholar]

3. Braveman P, Egerter S, Williams DR. The social determinants of health: coming of age. Annu Rev Public Health. 2011;32():381-98. [Pubmed] [Google Scholar]

4. Cardiovascular diseases and its social determinants of health with reference to low- and middle-income countries- A Self Study Module. Course convenor: Dr (Prof) B. N. Mishra. Institute: R D GMC, Ujjain. The ARCADE (African/Asian Regional Capacity Development) RSDH; Building Capacity for research on Social Determinants on Health in Asia projects. $7^{\text {Th }}$ Frame work programme. European Union. 2015.

5. Solomon LS, Kanter MH. Health care steps up to social determinants of health: current context. Perm J. 2018;22:18-139. doi:10.7812/TPP/18-139. [Pubmed] [Google Scholar]

6. Islam MM. Social determinants of health and related inequalities: confusion and implications. Front Public Health. 2019;7:11. doi:10.3389/fpubh.2019.00011. [Pubmed] [Google Scholar]

7. Bronfenbrenner U. Toward an experimental ecology of human development. American Psychologist. 1977:32;513-531. [Google Scholar]

8. Espelage DL. Ecological theory: Preventing youth bullying, aggression, and victimization. Theory into Practice. 2014:53;257-264. doi:10.1080/00405841.2 014.947216. [Google Scholar]

9. Strategy Handbook [Internet]. Rashtriya Kishor Swasthya Karyakram. Adolescent Health Division Ministry of Health and Family Welfare Government of India. January 2014 [cited 2014 September 8]. Available from: https://www.dropbox.com/s/0oj4p422y7st4ku/ RKSK\%20Strategy\%20Handbook.pdf.

10. Pandit P. Teaching mathematics through dialogue method: an innovative practice for holistic education at elementary school level. Int J Recent Res Aspects. 2017:4(3);206-9. [Google Scholar]

11. Issah Iddrisu. Universal basic education policy: impact on enrolment and retention. J Edu Pract. 2016:7;17. [Google Scholar]

12. Ministry of Education [Internet]. National Education Policy 2020 [cited 2021 Jan 26]. Available from: https:// www.education.gov.in/sites/upload_files/mhrd/files/ NEP_Final_English_0.pdf.

13. Kshirsagar VY, Agarwal R, Sandeep B Bavdekar; Bullying in Schools: Prevalence and Short-term Impact. Indian Pediatrics. 2007:44(January 17);25-8. [Pubmed] [Google Scholar]

14. World Health Organization, Commission on Social Determinants of Health [Internet]. Closing the gap in a generation: health equity through action on the social determinants of health 2008 [cited 2021 Jan 27]. Geneva: WHO; 2008. Available from: http://www.who. int/social_determinants/thecommission/finalreport/ en/

15. Braveman P, Gottlieb L. The social determinants of health: it's time to consider the causes of the causes. Public Health Rep. 2014;129(Suppl 2):19-31. doi:10.1177/00333549141291S206. [Pubmed] [Google Scholar]

16. WHO. Social determinants of health and well-being among young people: Health Behaviour in School-Aged Children (HBSC) study: international report from the 2009/2010 survey. In: Candace C, Zanotti C, Morgan A, Currie D, de Looze M, Roberts C, Samdal O, Smith ORF, Barnekow V, editors. ISBN 9789289014236.

17. Braveman P, Egerter S, Williams DR. The social determinants of health: coming of age. Annu Rev Public Health. 2011;32:381-98. [Pubmed] [Google Scholar]

18. Han S, Lee H-S. Social capital and depression: does household context matter? Asia Pac J Public Health. 2015;27(2):NP2008-NP18. 10.1177/1010539513496140. [Pubmed] [Google Scholar]

19. Reibling N, Beckfield J, Huijts T, Schmidt-Catran A, Thomson $\mathrm{KH}$, Wendt C. Depressed during the depression: has the economic crisis affected mental health inequalities in Europe? Findings from the European Social Survey (2014) special module on the determinants of health. Eur J Public Health. 2017;27(suppl_1):47-54. [Pubmed] [Google Scholar]

20. Alegría M, NeMoyer A, Falgàs Bagué I, Wang Y, Alvarez K. Social determinants of mental health: where we are and where we need to go. Curr Psychiatry Rep. 2018;20(11):95. doi:10.1007/s11920-018-0969-9. [Pubmed] [Google Scholar]

21. Catherine Bradshaw, Tracy Evian Waasdorp. Measuring and Changing a "Culture of Bullying." 
School Psychol Rev. 2009;38(3);356-61. DOI: 10.1080/02796015.2009.12087820. [Google Scholar]

22. Mazur J, Tabak I. Determinants of bullying at school depending on the type of community: ecological analysis of secondary schools in Poland. School Mental Health. 2017:9;132-42. DOI 10.1007/s12310-017-92067. [Google Scholar]

23. Pepler D, Jiang D, Craig W, Connolly J. Developmental trajectories of bullying and associated factors. Child Dev. 2008 Mar-Apr;79(2):325-38. [Google Scholar]

24. Cook CR, Williams KR, Guerra NG, Kim TE, Sadek $S$. Predictors of bullying and victimization in childhood and adolescence: A meta-analytic investigation. School Psychol Quart. 2010:25(2);65-83. [Google Scholar]

25. Tippett N, Wolke D. Socioeconomic status and bullying: a meta-analysis. Am J Public Health. 2014;104: e48-e59. doi:10.2105/AJPH.2014.301960. [Pubmed] [Google Scholar]

26. Chaux E, Molano A, Podlesky P. Socio-economic, sociopolitical and socio-emotional variables explaining school bullying: a country-wide multilevel analysis. Aggress Behav. 2009 Nov-Dec;35(6):520-9. [Pubmed] [Google Scholar]

27. Card, N. (2003). Victims of peer aggression: A metaanalytic review. In: Card N, Nishina A, editors. Whipping boys and other victims of peer aggression: Twenty-five years of research, now where do we go? Innovative poster symposium presented at the biennial meeting of the society for research on child development. Tampa, FL, April 24-27, 2003. [Google Scholar]

28. Clayton R. Cook, Kirk R. Williams, Nancy G. Guerra, Tia E. Kim, Shelly Sadek. Predictors of bullying and victimization in childhood and adolescence: a meta-analytic Investigation. School Psychol Quart. 2010:25(2);65-83. [Google Scholar]

29. WHO/Europe [Internet]. Health 2020 [cited 2021 jan 25]. http://www.euro.who.int

30. Mishra B, Patidar S, Sinha N D, Mohapatra S C, Distribution and correlations of school bully activities in a Central Indian district of Madhya Pradesh. J Community Health Manag. 2021;8(1):53-57. https:// doi.org/10.18231/j.jchm.2021.012. [Google Scholar]

31. Mishra B, Patidar S, Sinha ND, Mishra B, Mishra G. Relationships of School Performance and Responsibilitysharing with Bully Activities in Indian Schools. J Adv Res Med Sci Tech. 2021; 8(2):7-11. https://doi. org/10.24321/2394.6539.202105. [Google Scholar] 